\title{
EFIKASI HERBISIDA FLUMIOXAZIN PADA GULMA PERTANAMAN TEBU (Saccharum officinarum L. ) LAHAN KERING KEPRASAN 1
}

\author{
Agus Pariyanto, Dad R. J. Sembodo \& Sugiatno \\ Jurusan Agroteknologi Fakultas Pertanian Universitas Lampung \\ Jl. Prof. Dr. Soemantri Brojonegoro No. 1 Bandar Lampung 35145 \\ E-mail: pariyantoagus93@yahoo.co.id
}

\begin{abstract}
ABSTRAK
Tujuan penelitian adalah mempelajari efikasi herbisida flumioxazin dalam mengendalikan gulma pada pertanaman tebu dan pertumbuhan (tinggi dan populasi) tanaman tebu akibat aplikasi herbisida flumioxazin. Penelitian dilakukan di Desa Hajimena, Kecamatan Natar, Kabupaten Lampung Selatan dan Laboratorium Gulma Universitas Lampung pada bulan Desember 2013 hingga Maret 2014. Rancangan percobaan yang digunakan yaitu rancangan kelompok teracak sempurna (RKTS). Percobaan terdiri atas 10 perlakuan dan diulang sebanyak tiga kali. Perlakuan terdiri atas taraf dosis flumioxazin 75, 100, 150, 200, dan 250 $\mathrm{g} \mathrm{ha}^{-1}$, diuron 1396,6 $\mathrm{g} \mathrm{ha}^{-1}+$ hexaxinon 403,4 $\mathrm{g} \mathrm{ha}^{-1}$, imazapik $75 \mathrm{~g} \mathrm{ha}^{-1}+$ pendimetalin $750 \mathrm{~g} \mathrm{ha}^{-1}$, metribuzin $875 \mathrm{~g} \mathrm{ha}^{-1}$, tanpa perlakuan (kontrol), dan penyiangan mekanis. Homogenitas ragam data diuji dengan uji Bartlett dan aditivitas data diuji dengan uji Tukey. Perbedaan nilai tengah di uji dengan uji beda nyata terkecil (BNT) pada taraf nyata 5\%. Peubah yang diamati yaitu bobot kering gulma (total, golongan, dan dominan), pertumbuhan (populasi, dan tinggi) tanaman tebu. Hasil penelitian menunjukkan bahwa semua taraf dosis herbisida flumioxazin yang diuji $\left(75-250 \mathrm{~g} \mathrm{ha}^{-1}\right)$ efektif mengendalikan gulma total, golongan daun lebar dan gulma Richardia brasiliensis pada 30, 60, dan 90 hari setelah aplikasi (HSA). Herbisida flumioxazin dosis 200 dan $250 \mathrm{~g} \mathrm{ha}^{-1}$ efektif mengendalikan gulma Mimosa invisa pada 30, 60, dan 90 HSA. Herbisida flumioxazin pada semua taraf dosis yang diuji $\left(75-250 \mathrm{~g} \mathrm{ha}^{-1}\right)$ tidak berpengaruh terhadap pertumbuhan (tinggi dan populasi) tanaman tebu pada 30,60 , dan 90 HSA..
\end{abstract}

Kata kunci: efikasi, gulma, herbisida flumioxazin, tebu.

\section{PENDAHULUAN}

Menurut Kuntohartono (1991) dalam Alfredo dkk. (2012) kerugian yang ditimbulkan oleh keberadaan gulma pada pertanaman tebu yaitu dapat menurunkan bobot tebu berkisar 6- 9\% dan penurunan rendemen sebesar 0,09\%. Kompetisi gulma pada 3, 6, dan 9 minggu setelah tanam akan menurunkan hasil tanaman tebu berturut-turut sebesar $77,6 \%, 50,6 \%$, dan $41,7 \%$ (Zimdahl (1980) dalam Wijaya dkk., 2012). Oleh karena itu, tindakan pengendalian gulma penting untuk dilakukan.

Tindakan pengendalian untuk mencegah dan mengurangi kerugian secara ekonomi akibat adanya gulma pada periode kritis tanaman tebu yaitu dengan penggunaan herbisida pratumbuh salah satunya bahan aktif flumioxazin. Herbisida flumioxazin dapat digunakan secara pratumbuh dan pasca tumbuh. Cara kerja herbisida flumioxazin yaitu menghambat kerja enzim protoporphyrinogen oxidase. Herbisida berbahan aktif flumioxazin banyak digunakan untuk mengendalikan gulma tahunan rumput, daun lebar dan teki (Tomlin, 2011).

Efektivitas penggunaan herbisida sangat ditentukan oleh dosis yang diberikan, sehingga pemberian dosis harus tepat (Sembodo, 2010). Flessner dkk. (2013) melaporkan bahwa herbisida flumioxazin dengan dosis $0,43 \mathrm{~kg} \mathrm{ha}^{-1}$ mampu mengendalikan $95 \%$ gulma Poa annua. Hal serupa juga telah dilaporkan sebelumnya oleh Ducar dkk. (2002) bahwa perlakuan kombinasi herbisida diklosulam, flumioxazin, dan imazapik pada pertanaman kacang tanah menunjukkan persentase pengendalian gulma lebih dari $84 \%$ dan diiringi oleh hasil yang lebih tinggi dibandingkan dengan tanpa aplikasi herbisida serta tidak menimbulkan pengaruh buruk terhadap kacang tanah. Selain itu, menurut Vasilakoglou dkk. (2013) herbisida flumioxazin efektif mengendalikan gulma daun lebar seperti genus Amaranthus.

Hasil penelitian Grichar dkk. (2013) penggunaan herbisida flumioxazin yang diaplikasikan tidak mengkerdilkan tanaman kacang tanah. Hal serupa juga diungkapkan oleh Tomlin (2011) bahwa kedelai dan kacang tanah toleran sedangkan pada jagung, gandum, barley dan padi agak toleran terhadap flumioxazin. Pengetahuan akan penggunaan dosis herbisida flumioxazin pada pertanaman tebu belum diketahui secara pasti. Penelitian ini bertujuan untuk mempelajari beberapa tingkat dosis herbisida flumioxazin yang efektif dalam mengendalikan gulma pada pertanaman tebu lahan kering keprasan 1 dan mempelajari pertumbuhan 
tanaman tebu lahan kering keprasan 1 akibat aplikasi herbisida flumioxazin.

\section{BAHAN DAN METODE}

Penelitian dilaksanakan di Hajimena, Kecamatan Natar, Kabupaten Lampung Selatan dan di Laboratorium Gulma Universitas Lampung pada bulan Desember 2013 hingga Maret 2014. Alat- alat yang digunakan dalam penelitian ini adalah Knapscak sprayer gelas ukur, meteran, pipet ukur, timbangan, oven, ember plastik, dan cangkul. Bahan yang digunakan adalah tebu ratoon 1 klon RGM 97 - 10120, pupuk NPK PHONSKA, Urea, air, herbisida berbahan aktif flumioxazin (Sumimax 50WP), diuron+ hexaxinon (Velpar $60 \mathrm{WG}$ ), metribuzin (Sencor 70 WP), imazapik (Cadre 240 SL), dan pendimetalin (Prowl 330 EC).

Penelitian ini menggunakan rancangan percobaan kelompok teracak sempurna (RKTS). Percobaan terdiri atas 10 perlakuan (Tabel 1) dan diulang sebanyak tiga kali. Homogenitas ragam data diuji dengan uji Bartlett dan aditivitas data diuji dengan uji Tukey. Perbedaan nilai tengah di uji dengan uji beda nyata terkecil (BNT) pada taraf nyata $5 \%$. Setiap plot berukuran $5 \mathrm{~m} \mathrm{x} 5 \mathrm{~m}$ dan terdiri dari 5 baris tanaman tebu dengan jarak antar baris $1 \mathrm{~m}$. Volume semprot yang digunakan yaitu $400 \mathrm{~L}$ ha $^{-1}$. Peubah yang diamati pada percobaan ini meliputi Bobot kering gulma total, golongan daun lebar, dan golongan rumput, serta pertumbuhan (tinggi dan populasi) tanaman tebu. Deskripsi metode pengamatan yaitu sebagai berikut:

Bobot kering gulma didapatkan dengan cara mengambil gulma pada petak pengambilan gulma menggunakan metode kuadran ukuran $50 \mathrm{~cm}$ x $50 \mathrm{~cm}$, gulma yang akarnya berada di dalam lingkup kuadran dipotong tepat setinggi permukaan tanah dan dipisahkan berdasarkan golongan dan spesiesnya. Gulma dioven selama 48 jam dengan suhu $80{ }^{\circ} \mathrm{C}$ hingga bobot gulma konstan dan dilakukan pada 30, 60, dan 90 hari setelah aplikasi (HSA). Pengamatan tinggi tanaman yaitu dengan menetapkan 15 tanaman contoh yang berada ditengah petak percobaan dan dilakukan pada 30,60, dan 90 HSA. Pengamataan populasi tanaman tebu yaitu dengan menghitung jumlah populasi tebu yang berada di 3 baris tengah (tanaman per $15 \mathrm{~m}$ ) dan dilakukan pada 30,60 , dan 90 HSA.

\section{HASIL DAN PEMBAHASAN}

Bobot Kering Gulma Total. Herbisida flumioxazin pada semua dosis yang diuji (75 - $250 \mathrm{~g} \mathrm{ha}^{-1}$ ) efektif menekan pertumbuhan gulma total mulai dari 30, 60, dan 90 HSA (Tabel 2). Hasil ini sejalan dengan pendapat Tomlin (2011) bahwa herbisida flumioxazin merupakan herbisida non selektif artinya efektif mengendalikan gulma dari golongan daun lebar, rumput, dan teki. Herbisida flumioxazin dapat menekan gulma pada 90 HSA yaitu antara $71-88 \%$ dan hasil yang sama efektifnya dengan metode pengendalian diuron + hexaxinon $(1396,6+403,4) \mathrm{g} \mathrm{ha}^{-1}$, imazapik + pendimetalin $(75+750) \mathrm{g} \mathrm{ha}^{-1}$ dan metribuzin $875 \mathrm{~g} \mathrm{ha}^{-1}$ dalam menekan pertumbuhan gulma total menunjukkan bahwa herbisida flumioxazin dapat digunakan sebagai herbisida pratumbuh di perkebunan tebu.

Bobot Kering Gulma Golongan Daun Lebar. Herbisida flumioxazin yang diuji $\left(75-250 \mathrm{~g} \mathrm{ha}^{-1}\right)$ efektif mengendalikan gulma golongan daun lebar pada 30,60,

Tabel 1. Susunan perlakuan efikasi herbisida flumioxazin

\begin{tabular}{|c|c|c|c|c|}
\hline No & Perlakuan & $\begin{array}{c}\text { Dosis Bahan Aktif } \\
\qquad\left(\mathrm{g} \mathrm{ha}^{-1}\right)\end{array}$ & $\begin{array}{l}\text { Dosis Formulasi } \\
\left(\mathrm{g} \text { atau } \mathrm{ml} \mathrm{ha}^{-1}\right)\end{array}$ & $\begin{array}{c}\text { Waktu Aplikasi } \\
\text { (HST) }\end{array}$ \\
\hline 1 & Flumioxazin & $75 \mathrm{~g}$ & $150 \mathrm{~g}$ & 7 \\
\hline 2 & Flumioxazin & $100 \mathrm{~g}$ & $200 \mathrm{~g}$ & 7 \\
\hline 3 & Flumioxazin & $150 \mathrm{~g}$ & $300 \mathrm{~g}$ & 7 \\
\hline 4 & Flumioxazin & $200 \mathrm{~g}$ & $400 \mathrm{~g}$ & 7 \\
\hline 5 & Flumioxazin & $250 \mathrm{~g}$ & $500 \mathrm{~g}$ & 7 \\
\hline 6 & Diuron+ Hexaxinon & $(1396,6+403,4) \mathrm{g}$ & $3000 \mathrm{~g}$ & 10 \\
\hline 7 & Imazapik+Pendimetalin & $(75+750) \mathrm{g}$ & $(312,5+2272,7) \mathrm{ml}$ & 7 \\
\hline 8 & Metribuzin & $875 \mathrm{~g}$ & $1250 \mathrm{~g}$ & 7 \\
\hline 9 & Kontrol & - & - & - \\
\hline 10 & Penyiangan mekanis & - & - & $*$ \\
\hline
\end{tabular}

Keterangan:HST: hari setelah tebang, *: perlakuan penyianan mekanis dilakukan sebanyak 2 kali yaitu 30 dan 60 HSA 
Tabel 2. Pengaruh herbisida flumioxazin terhadap bobot kering total

\begin{tabular}{|c|c|c|c|c|c|c|}
\hline \multirow{3}{*}{ Perlakuan } & \multicolumn{2}{|c|}{$30 \mathrm{HSA}$} & \multicolumn{2}{|c|}{$60 \mathrm{HSA}$} & \multicolumn{2}{|c|}{$90 \mathrm{HSA}$} \\
\hline & Asli & $\begin{array}{c}\text { Trans } \\
\operatorname{vvv}(x+0,5)\end{array}$ & Asli & $\begin{array}{c}\text { Trans } \\
\mathrm{v}(\mathrm{x}+0,5)\end{array}$ & Asli & $\begin{array}{c}\text { Trans } \\
\mathrm{v}(\mathrm{x}+0,5)\end{array}$ \\
\hline & \multicolumn{6}{|c|}{$\left(\mathrm{g} / 0,5 \mathrm{~m}^{2}\right) \ldots .}$. \\
\hline Flumioxazin $75 \mathrm{~g} \mathrm{ha}^{-1}$ & 1,4 & $1,1 \mathrm{~b}$ & 55,2 & $7,4 \mathrm{~b}$ & 57,1 & $7,3 \mathrm{bc}$ \\
\hline Flumioxazin $100 \mathrm{~g} \mathrm{ha}^{-1}$ & 0,4 & $0,9 \mathrm{~cd}$ & 13,3 & $3,1 \mathrm{c}$ & 45,9 & $6,1 \mathrm{bcd}$ \\
\hline Flumioxazin $150 \mathrm{~g} \mathrm{ha}^{-1}$ & 0,5 & $0,9 \mathrm{~cd}$ & 4,5 & $1,7 \mathrm{c}$ & 20,5 & $3,8 \mathrm{~cd}$ \\
\hline Flumioxazin $200 \mathrm{~g} \mathrm{ha}^{-1}$ & 0,0 & $0,9 \mathrm{~d}$ & 3,5 & $1,7 \mathrm{c}$ & 3,7 & $2,0 \mathrm{~d}$ \\
\hline Flumioxazin $250 \mathrm{~g} \mathrm{ha}^{-1}$ & 0,1 & $0,9 \mathrm{~d}$ & 2,2 & $1,5 \mathrm{c}$ & 6,7 & $2,3 \mathrm{~d}$ \\
\hline $\begin{array}{l}\text { Diuron + Hexaxinon } \\
(1396,6+403,4) \mathrm{g} \mathrm{ha}^{-1}\end{array}$ & 0,1 & $0,9 \mathrm{~d}$ & 24,7 & $3,4 \mathrm{c}$ & 15,0 & $3,5 \mathrm{~cd}$ \\
\hline $\begin{array}{l}\text { Imazapik+Pendimetalin } \\
(75+750) \mathrm{g} \mathrm{ha}^{-1}\end{array}$ & 0,4 & $0,9 \mathrm{~cd}$ & 11,5 & $3,3 \mathrm{c}$ & 54,4 & $7,1 \mathrm{bc}$ \\
\hline Metribuzin $875 \mathrm{~g} \mathrm{ha}^{-1}$ & 1,1 & $1,0 \mathrm{bc}$ & 15,8 & $3,7 \mathrm{c}$ & 63,1 & $7,8 \mathrm{bc}$ \\
\hline Kontrol & 15,1 & $1,4 \mathrm{a}$ & 214,6 & $14,4 \mathrm{a}$ & 193,6 & $13,6 \mathrm{a}$ \\
\hline Penyiangan mekanis & 16,8 & $1,4 \mathrm{a}$ & 15,8 & $3,9 \mathrm{bc}$ & 92,6 & $9,5 \mathrm{ab}$ \\
\hline BNT 0,05 & & 0,1 & & 3,7 & & 4,5 \\
\hline
\end{tabular}

Keterangan: Nilai tengah yang diikuti oleh huruf yang sama pada kolom yang sama tidak berbeda menurut uji BNT pada taraf nyata $5 \%$.

dan 90 HSA (Tabel 3). Hasil ini sejalan dengan pendapat Vasilakoglou dkk. (2013) bahwa herbisida berbahan aktif flumioxazin efektif mengendalikan gulma daun lebar seperti genus Amaranthus. Kemampuan herbisida flumioxazin dalam menekan pertumbuhan gulma golongan daun lebar pada 90 HSA yaitu antara 50 - 85 $\%$ dan hasil yang sama efektifnya dengan herbisida diuron + hexaxinon $(1396,6+403,4) \mathrm{g} \mathrm{ha}^{-1}$, imazapik +

Tabel 3. Pengaruh herbisida flumioxazin terhadap bobot kering gulma daun lebar

\begin{tabular}{|c|c|c|c|c|c|c|}
\hline \multirow{3}{*}{ Perlakuan } & \multicolumn{2}{|c|}{$30 \mathrm{HSA}$} & \multicolumn{2}{|c|}{$60 \mathrm{HSA}$} & \multicolumn{2}{|c|}{$90 \mathrm{HSA}$} \\
\hline & Asli & $\begin{array}{c}\text { Trans } \\
\operatorname{vvv}(x+0,5) \\
\end{array}$ & Asli & $\begin{array}{c}\text { Trans } \\
\mathrm{vv}(\mathrm{x}+0,5)\end{array}$ & Asli & $\begin{array}{c}\text { Trans } \\
\mathrm{v}(\mathrm{x}+0,5) \\
\end{array}$ \\
\hline & \multicolumn{6}{|c|}{$\left(\mathrm{g} / 0,5 \mathrm{~m}^{2}\right)$} \\
\hline Flumioxazin $75 \mathrm{~g} \mathrm{ha}^{-1}$ & 1,2 & $1,1 \mathrm{~b}$ & 42,2 & $2,5 \mathrm{~b}$ & 57,2 & $7,3 \mathrm{bcd}$ \\
\hline Flumioxazin $100 \mathrm{~g} \mathrm{ha}^{-1}$ & 0,4 & $0,9 \mathrm{bc}$ & 13,3 & $1,6 \mathrm{cdef}$ & 44,0 & 5,9 bcde \\
\hline Flumioxazin $150 \mathrm{~g} \mathrm{ha}^{-1}$ & 0,5 & $0,9 \mathrm{bc}$ & 4,5 & $1,2 \mathrm{cdef}$ & 18,4 & $3,1 \mathrm{def}$ \\
\hline Flumioxazin $200 \mathrm{~g} \mathrm{ha}^{-1}$ & 0,0 & $0,9 \mathrm{c}$ & 1,8 & $1,1 \mathrm{ef}$ & 3,7 & $2,0 \mathrm{ef}$ \\
\hline Flumioxazin $250 \mathrm{~g} \mathrm{ha}^{-1}$ & 0,1 & $0,9 \mathrm{c}$ & 1,8 & $1,2 \mathrm{def}$ & 0,7 & $1,0 \mathrm{f}$ \\
\hline Diuron + Hexaxinon & & & & & & \\
\hline$(1396,6+403,4) \mathrm{g} \mathrm{ha}^{-1}$ & 0,0 & $0,9 \mathrm{c}$ & 0,3 & $0,9 \mathrm{f}$ & 15,1 & $3,5 \mathrm{cdef}$ \\
\hline $\begin{array}{l}\text { Imazapik+Pendimetalin } \\
(75+750) \mathrm{g} \mathrm{ha}^{-1}\end{array}$ & 0,0 & $0,9 \mathrm{c}$ & 8,1 & $1,7 \mathrm{bcde}$ & 48,9 & $6,8 \mathrm{bcd}$ \\
\hline Metribuzin $875 \mathrm{~g} \mathrm{ha}^{-1}$ & 0,9 & $1,0 \mathrm{~b}$ & 15,8 & $1,8 \mathrm{bcd}$ & 63,1 & $7,8 \mathrm{bc}$ \\
\hline Kontrol & 15,0 & $1,4 \mathrm{a}$ & 214,6 & $3,8 \mathrm{a}$ & 192,7 & $13,5 \mathrm{a}$ \\
\hline Penyiangan mekanis & 16,7 & $1,4 \mathrm{a}$ & 15,8 & $1,9 \mathrm{bc}$ & 92,7 & $9,5 \mathrm{ab}$ \\
\hline BNT 0,05 & & 0,1 & & 0.7 & & 4.4 \\
\hline
\end{tabular}

Keterangan: Nilai tengah yang diikuti oleh huruf yang sama pada kolom yang sama tidak berbeda menurut uji BNT pada taraf nyata $5 \%$. 
pendimetalin $(75+750) \mathrm{g} \mathrm{ha}^{-1}$ dan metribuzin $875 \mathrm{~g} \mathrm{ha}^{-1}$ dalam menekan pertumbuhan gulma golongan daun lebar menunjukkan bahwa herbisida flumioxazin dapat digunakan sebagai herbisida pratumbuh di perkebunan tebu yang didominasi oleh gulma daun lebar.

Bobot Kering Richardia brasiliensis. Herbisida flumioxazin pada semua dosis yang diuji $(75-250 \mathrm{~g}$ $\mathrm{ha}^{-1}$ ) efektif menekan pertumbuhan gulma Richardia brasiliensis pada 30, 60, dan 90 HSA (Tabel 4). Hasil ini sejalan dengan pnelitian Azania dkk. (2010) bahwa herbisida berbahan aktif flumioxazin mampu mengendalikan gulma daun lebar. Richardia brasiliensis merupakan salah satu gulma golongan daun lebar, sehingga herbisida flumioxazin efektif mengendalikan pertumbuhan Richardia brasiliensis. Herbisida flumioxazin mampu menekan pertumbuhan gulma Richardia brasiliensis antara $26-31 \%$ dan memberikan hasil yang sama efektifnya dengan herbisida diuron + hexaxinon $(1396,6+403,4) \mathrm{g} \mathrm{ha}^{-1}$, imazapik + pendimetalin $(75+750) \mathrm{g} \mathrm{ha}^{-1}$ dan metribuzin $875 \mathrm{~g} \mathrm{ha}^{-1}$ dalam menekan pertumbuhan gulma Richardia brasiliensis. Hasil ini menunjukkan bahwa herbisida flumioxazin dapat digunakan sebagai herbisida pratumbuh di perkebunan tebu yang didominasi oleh gulma Richardia brasiliensis.
Bobot Kering Gulma Mimosa invisa. Herbisida flumioxazin pada semua taraf dosis yang diuji (75 - $250 \mathrm{~g} \mathrm{ha}^{-1}$ ) efektif menekan pertumbuhan gulma Mimosa invisa pada $30 \mathrm{HSA}$, dosis $\left(100-250 \mathrm{~g} \mathrm{ha}^{-1}\right)$ efektif pada $60 \mathrm{HSA}$, dan dosis (200 - $250 \mathrm{~g} \mathrm{ha}^{-1}$ ) efektif pada 90 HSA (Tabel 5). Kemampuan herbisida flumioxazin pada dosis 200 dan $250 \mathrm{~g} \mathrm{ha}^{-1}$ dalam menekan pertumbuhan gulma Mimosa invisa pada 90 HSA yaitu antara $14-15 \%$ dan hasil yang sama efektif dengan herbisida diuron + hexaxinon $(1396,6+403,4)$ $\mathrm{g} / \mathrm{ha}$, imazapik + pendimetalin $(75+750) \mathrm{g} \mathrm{ha}^{-1}$ dan metribuzin $875 \mathrm{~g} \mathrm{ha}^{-1}$ menunjukkan herbisida flumioxazin dapat dijadikan herbisida pratumbuh di perkebunan tebu dengan kondisi terjadi dominasi gulma Mimosa invisa.

Bobot Kering Golongan Rumput. Kondisi gulma golongan rumput di petak percobaan sampai dengan 90 HSA sangat kecil sehingga secara visual tidak terlihat perbedaan dengan kontrol (Tabel 6). Selain itu juga, kondisi gulma golongan rumput pada petak percobaan kontrol dari 30 sampai dengan 90 HSA tidak ada (nol) sehingga ketika dibandingkan dengan perlakuan semua metode pengendalian gulma yang diuji tidak terdapat perbedaan dalam penekanan pertumbuhan gulma rumput.

Tabel 4. Pengaruh herbisida flumioxazin terhadap bobot kering Ricardia brasiliensis

\begin{tabular}{|c|c|c|c|c|c|c|}
\hline \multirow{3}{*}{ Perlakuan } & \multicolumn{2}{|c|}{$30 \mathrm{HSA}$} & \multicolumn{2}{|c|}{$60 \mathrm{HSA}$} & \multicolumn{2}{|c|}{$90 \mathrm{HSA}$} \\
\hline & Asli & $\begin{array}{c}\text { Trans } \\
\operatorname{vvv}(x+0,5)\end{array}$ & Asli & $\begin{array}{c}\text { Trans } \\
\operatorname{vv}(x+0,5)\end{array}$ & Asli & $\begin{array}{c}\text { Trans } \\
\mathrm{v}(\mathrm{x}+0,5)\end{array}$ \\
\hline & \multicolumn{6}{|c|}{$\left(\mathrm{g} / 0,5 \mathrm{~m}^{2}\right)$} \\
\hline Flumioxazin $75 \mathrm{~g} \mathrm{ha}^{-1}$ & 0,0 & $0,9 \mathrm{~b}$ & 0,9 & $1,0 \mathrm{~cd}$ & 7,0 & $1,1 \mathrm{bc}$ \\
\hline Flumioxazin $100 \mathrm{~g} \mathrm{ha}^{-1}$ & 0,0 & $0,9 \mathrm{~b}$ & 1,8 & $1,0 \mathrm{~cd}$ & 6,2 & $1,2 \mathrm{bc}$ \\
\hline Flumioxazin $150 \mathrm{~g} \mathrm{ha}^{-1}$ & 0,0 & $0,9 \mathrm{~b}$ & 0,0 & $0,9 \mathrm{~d}$ & 0,0 & $0,9 \mathrm{c}$ \\
\hline Flumioxazin $200 \mathrm{~g} \mathrm{ha}^{-1}$ & 0,0 & $0,9 \mathrm{~b}$ & 0,0 & $0,9 \mathrm{~d}$ & 1,2 & $1,0 \mathrm{c}$ \\
\hline Flumioxazin $250 \mathrm{~g} \mathrm{ha}^{-1}$ & 0,0 & $0,9 \mathrm{~b}$ & 0,0 & $0,9 \mathrm{~d}$ & 0,7 & $1,0 \mathrm{bc}$ \\
\hline Diuron + Hexaxinon & & & & & & \\
\hline$(1396,6+403,4) \mathrm{g} \mathrm{ha}^{-1}$ & 0,0 & $0,9 \mathrm{~b}$ & 0,2 & $0,9 \mathrm{~d}$ & 11,7 & $1,1 \mathrm{bc}$ \\
\hline Imazapik+Pendimetalin & 0.0 & $0.9 \mathrm{~b}$ & 59 & $12 \mathrm{bc}$ & 53 & $11 \mathrm{hc}$ \\
\hline Metribuzin $875 \mathrm{~g} \mathrm{ha}^{-1}$ & 0,4 & $0,9 \mathrm{~b}$ & $\begin{array}{r}J, 3 \\
12,3\end{array}$ & $1,3 \mathrm{~b}$ & 21,7 & $1,4 \mathrm{ab}$ \\
\hline Kontrol & 7,8 & $1,3 \mathrm{a}$ & 162,8 & $1,8 \mathrm{a}$ & 59,7 & $1,6 \mathrm{a}$ \\
\hline Penyiangan mekanis & 10,4 & $1,3 \mathrm{a}$ & 15,2 & $1,4 \mathrm{~b}$ & 78,9 & $1,7 \mathrm{a}$ \\
\hline BNT 0,05 & & 0,1 & & 0,2 & & 0,4 \\
\hline
\end{tabular}

Keterangan: Nilai tengah yang diikuti oleh huruf yang sama pada kolom yang sama tidak berbeda menurut uji BNT pada taraf nyata $5 \%$. 
Tabel 5. Pengaruh herbisida flumioxazin terhadap bobot kering Mimosa invisa

\begin{tabular}{|c|c|c|c|c|c|c|}
\hline \multirow[b]{2}{*}{ Perlakuan } & \multicolumn{2}{|c|}{30 HSA } & \multicolumn{2}{|c|}{$60 \mathrm{HSA}$} & \multicolumn{2}{|c|}{90 HSA } \\
\hline & Asli & $\begin{array}{c}\text { Trans } \\
\operatorname{vvv}(x+0,5)\end{array}$ & Asli & $\begin{array}{c}\text { Trans } \\
\mathrm{vv}(\mathrm{x}+0,5)\end{array}$ & Asli & $\begin{array}{c}\text { Trans } \\
\mathrm{v}(\mathrm{x}+0,5)\end{array}$ \\
\hline & \multicolumn{6}{|c|}{ 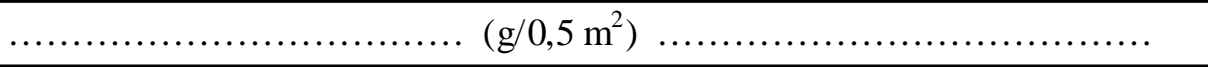 } \\
\hline Flumioxazin $75 \mathrm{~g} \mathrm{ha}^{-1}$ & 0,4 & $0,9 \mathrm{c}$ & 23,4 & $1,4 \mathrm{a}$ & 41,8 & $1,4 \mathrm{a}$ \\
\hline Flumioxazin $100 \mathrm{~g} \mathrm{ha}^{-1}$ & 0,0 & $0,9 \mathrm{~d}$ & 5,5 & $1,1 \mathrm{~b}$ & 27,9 & $1,3 \mathrm{ab}$ \\
\hline Flumioxazin $150 \mathrm{~g} \mathrm{ha}^{-1}$ & 0,0 & $0,9 \mathrm{~d}$ & 4,4 & $1,1 \mathrm{bc}$ & 11,1 & $1,1 \mathrm{ab}$ \\
\hline Flumioxazin $200 \mathrm{~g} \mathrm{ha}^{-1}$ & 0,0 & $0,9 \mathrm{~d}$ & 0,0 & $0,9 \mathrm{c}$ & 0,6 & $1,0 \mathrm{bc}$ \\
\hline Flumioxazin $250 \mathrm{~g} \mathrm{ha}^{-1}$ & 0,0 & $0,9 \mathrm{~d}$ & 1,8 & $1,1 \mathrm{bc}$ & 0,0 & $0,9 \mathrm{c}$ \\
\hline Diuron + Hexaxinon & & & & & & \\
\hline$(1396,6+403,4) \mathrm{g} \mathrm{ha}^{-1}$ & 0,0 & $0,9 \mathrm{~d}$ & 0,0 & $0,9 \mathrm{c}$ & 1,2 & $1,0 \mathrm{abc}$ \\
\hline $\begin{array}{l}\text { Imazapik+Pendimetalin } \\
(75+750) \mathrm{g} \mathrm{ha}^{-1}\end{array}$ & 0,0 & $0,9 \mathrm{~d}$ & 0,0 & $0,9 \mathrm{c}$ & 1,3 & $0,0 \mathrm{abc}$ \\
\hline Metribuzin $875 \mathrm{~g} \mathrm{ha}^{-1}$ & 0,0 & $0,9 \mathrm{~d}$ & 0,0 & $0,9 \mathrm{c}$ & 0,0 & $0,9 \mathrm{c}$ \\
\hline Kontrol & 1,8 & $1,1 \mathrm{a}$ & 21,8 & $1,5 \mathrm{a}$ & 17,0 & $1,4 \mathrm{a}$ \\
\hline Penyiangan mekanis & 0,8 & $1,0 \mathrm{~b}$ & 0,0 & $0,9 \mathrm{c}$ & 0,0 & $0,9 \mathrm{c}$ \\
\hline BNT 0,05 & & 0,1 & & 0,2 & & 0,4 \\
\hline
\end{tabular}

Keterangan: Nilai tengah yang diikuti oleh huruf yang sama pada kolom yang sama tidak berbeda menurut uji BNT pada taraf nyata $5 \%$.

Tabel 6. Pengaruh herbisida flumioxazin terhadap bobot kering gulma rumput

\begin{tabular}{|c|c|c|c|c|c|c|}
\hline \multirow[b]{2}{*}{ Perlakuan } & \multicolumn{2}{|c|}{30 HSA } & \multicolumn{2}{|c|}{60 HSA } & \multicolumn{2}{|c|}{$90 \mathrm{HSA}$} \\
\hline & Asli & $\begin{array}{c}\text { Trans } \\
\operatorname{vvv}(x+0,5)\end{array}$ & Asli & $\begin{array}{c}\text { Trans } \\
\operatorname{vv}(x+0,5)\end{array}$ & Asli & $\begin{array}{c}\text { Trans } \\
\mathrm{v}(\mathrm{x}+0,5)\end{array}$ \\
\hline & \multicolumn{6}{|c|}{$\ldots \ldots \ldots \ldots \ldots \ldots \ldots \ldots \ldots \ldots \ldots \ldots \ldots \ldots \ldots,\left(g / 0,5 \mathrm{~m}^{2}\right)$} \\
\hline Flumioxazin $75 \mathrm{~g} \mathrm{ha}^{-1}$ & 0,3 & $0,9 \mathrm{a}$ & 13,0 & $1,1 \mathrm{a}$ & 0,0 & $0,9 \mathrm{a}$ \\
\hline Flumioxazin $100 \mathrm{~g} \mathrm{ha}^{-1}$ & 0,0 & $0,9 \mathrm{a}$ & 0,0 & $0,9 \mathrm{a}$ & 1,9 & $1,0 \mathrm{a}$ \\
\hline Flumioxazin $150 \mathrm{~g} \mathrm{ha}^{-1}$ & 0,0 & $0,9 \mathrm{a}$ & 0,0 & $0,9 \mathrm{a}$ & 2,1 & $1,0 \mathrm{a}$ \\
\hline Flumioxazin $200 \mathrm{~g} \mathrm{ha}^{-1}$ & 0,0 & $0,9 \mathrm{a}$ & 1,7 & $1,1 \mathrm{a}$ & 0,0 & $0,9 \mathrm{a}$ \\
\hline Flumioxazin $250 \mathrm{~g} \mathrm{ha}^{-1}$ & 0,0 & $0,9 \mathrm{a}$ & 0,3 & $0,9 \mathrm{a}$ & 6,0 & $1,1 \mathrm{a}$ \\
\hline Diuron + Hexaxinon & & & & & & \\
\hline$(1396,6+403,4) \mathrm{g} \mathrm{ha}^{-1}$ & 0,1 & $0,9 \mathrm{a}$ & 24,4 & $1,1 \mathrm{a}$ & 0,0 & $0,9 \mathrm{a}$ \\
\hline Imazapik+Pendimetalin & & & & & & \\
\hline$(75+750) \mathrm{g} \mathrm{ha}^{-1}$ & 0,4 & $0,9 \mathrm{a}$ & 3,3 & $1,1 \mathrm{a}$ & 5,4 & $1,1 \mathrm{a}$ \\
\hline $\begin{array}{l}\text { Metribuzin } 875 \mathrm{~g} \mathrm{ha}^{-1} \\
\text { Kontrol }\end{array}$ & $\begin{array}{l}0,1 \\
0,0\end{array}$ & $\begin{array}{l}0,9 \mathrm{a} \\
0,9 \mathrm{a}\end{array}$ & $\begin{array}{l}0,0 \\
0,0\end{array}$ & $\begin{array}{l}0,9 \mathrm{a} \\
0,9 \mathrm{a}\end{array}$ & $\begin{array}{l}0,0 \\
0,0\end{array}$ & $\begin{array}{l}0,9 \mathrm{a} \\
0,9 \mathrm{a}\end{array}$ \\
\hline Penyiangan mekanis & 0,0 & $0,9 \mathrm{a}$ & 0,0 & $0,9 \mathrm{a}$ & 0,0 & $0,9 \mathrm{a}$ \\
\hline BNT 0,05 & & 0,1 & & 0,4 & & 0,3 \\
\hline
\end{tabular}

Keterangan: Nilai tengah yang diikuti oleh huruf yang sama pada kolom yang sama tidak berbeda menurut uji BNT pada taraf nyata $5 \%$.

Populasi Tanaman Tebu. Penggunaan herbisida flumioxazin pada semua taraf dosis yang diuji terhadap populasi tanaman tebu menunjukkan hasil yang sama dengan penyiangan mekanis (Tabel 7). Menurut Jordan dkk. (2009), penggunaan flumioxazin tidak menurunkan hasil kacang tanah, sehingga memungkinkan tidak 
Tabel 7. Pengaruh herbisida flumioxazin terhadap populasi tanaman tebu

\begin{tabular}{|c|c|c|c|}
\hline \multirow{2}{*}{ Perlakuan } & 30 HSA & 60 HSA & 90 HSA \\
\hline & \multicolumn{3}{|c|}{.............Tanaman/15 m............... } \\
\hline Flumioxazin $75 \mathrm{~g} \mathrm{ha}^{-1}$ & $292,0 \mathrm{a}$ & $290,0 \mathrm{a}$ & $193,0 \mathrm{a}$ \\
\hline Flumioxazin $100 \mathrm{~g} \mathrm{ha}^{-1}$ & $264,0 \mathrm{a}$ & $262,3 \mathrm{a}$ & $199,3 \mathrm{a}$ \\
\hline Flumioxazin $150 \mathrm{~g} \mathrm{ha}^{-1}$ & 311,7 a & $308,7 \mathrm{a}$ & $223,6 \mathrm{a}$ \\
\hline Flumioxazin $200 \mathrm{~g} \mathrm{ha}^{-1}$ & $268,0 \mathrm{a}$ & $272,0 \mathrm{a}$ & $219,7 \mathrm{a}$ \\
\hline Flumioxazin $250 \mathrm{~g} \mathrm{ha}^{-1}$ & $294,0 \mathrm{a}$ & 296,7 a & $232,7 \mathrm{a}$ \\
\hline Diuron + Hexaxinon & $307,3 \mathrm{a}$ & $291,3 \mathrm{a}$ & $233,3 \mathrm{a}$ \\
\hline$(1396,6+403,4) \mathrm{g} \mathrm{ha}^{-1}$ & $258,0 \mathrm{a}$ & $261,7 \mathrm{a}$ & $193,7 \mathrm{a}$ \\
\hline Imazapik+Pendimetalin & $317,0 \mathrm{a}$ & $305,3 \mathrm{a}$ & $217,7 \mathrm{a}$ \\
\hline$(75+750) \mathrm{g} \mathrm{ha}^{-1}$ & $292,3 \mathrm{a}$ & $269,3 \mathrm{a}$ & $174,7 \mathrm{a}$ \\
\hline Metribuzin $875 \mathrm{~g} \mathrm{ha}^{-1}$ & $266,7 \mathrm{a}$ & $289,0 \mathrm{a}$ & $207,7 \mathrm{a}$ \\
\hline B NT 0,05 & 88,9 & 90,6 & 68,7 \\
\hline
\end{tabular}

Keterangan: Nilai tengah yang diikuti oleh huruf yang sama pada kolom yang sama tidak berbeda menurut uji BNT pada taraf nyata $5 \%$.

berpengaruh terhadap pupulasi tanaman tebu. Penggunaan herbisida flumioxazin tidak berpengaruh buruk terhadap populasi tanaman tebu sehingga dapat dijadikan alternatif herbisida pratumbuh pada pertanaman tebu.

Tinggi Tanaman. Penggunaan herbisida flumioxazin pada semua taraf dosis yang diuji terhadap tinggi tanaman menunjukkan hasil yang sama dengan penyiangan mekanis (Tabel 8). Hasil penelitian ini sejalan dengan pendapat Grichar dkk. (2013) bahwa penggunaan herbisida flumioxazin yang diaplikasikan tidak mengkerdilkan tanaman kacang tanah. Penggunaan herbisida flumioxazin tidak berpengaruh buruk terhadap tinggi tanaman tebu sehingga dapat dijadikan herbisida pratumbuh pada pertanaman tebu.

\section{KESIMPULAN}

Berdasarkan hasil penelitian yang telah dilakukan dapat disimpulkan sebagai berikut: (1) Herbisida flumioxazin pada semua taraf dosis yang diuji $(75-250$ $\mathrm{g} \mathrm{ha}^{-1}$ ) efektif dalam mengendalikan pertumbuhan gulma total, golongan daun lebar dan gulma Richardia

Tabel 8. Pengaruh perlakuan pengendalian gulma terhadap tinggi tanaman

\begin{tabular}{|c|c|c|c|}
\hline \multirow{2}{*}{ Perlakuan } & 30 HSA & 60 HSA & $90 \mathrm{HSA}$ \\
\hline & \multicolumn{3}{|c|}{ 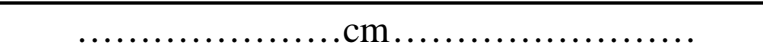 } \\
\hline Flumioxazin $75 \mathrm{~g} \mathrm{ha}^{-1}$ & $103,4 \mathrm{a}$ & $190,6 \mathrm{a}$ & $237,2 \mathrm{a}$ \\
\hline Flumioxazin $100 \mathrm{~g} \mathrm{ha}^{-1}$ & $105,7 \mathrm{a}$ & $185,8 \mathrm{a}$ & $242,8 \mathrm{a}$ \\
\hline Flumioxazin $150 \mathrm{~g} \mathrm{ha}^{-1}$ & $104,6 \mathrm{a}$ & $187,1 \mathrm{a}$ & $244,0 \mathrm{a}$ \\
\hline Flumioxazin $200 \mathrm{~g} \mathrm{ha}^{-1}$ & $112,7 \mathrm{a}$ & $194,8 \mathrm{a}$ & $247,6 \mathrm{a}$ \\
\hline Flumioxazin $250 \mathrm{~g} \mathrm{ha}^{-1}$ & $108,9 \mathrm{a}$ & $193,3 \mathrm{a}$ & $247,0 \mathrm{a}$ \\
\hline Diuron + Hexaxinon & $104,9 \mathrm{a}$ & $189,4 \mathrm{a}$ & $245,6 \mathrm{a}$ \\
\hline$(1396,6+403,4) \mathrm{g} \mathrm{ha}^{-1}$ & $101,2 \mathrm{a}$ & $191,1 \mathrm{a}$ & $246,2 \mathrm{a}$ \\
\hline Imazapik+Pendimetalin & $110,7 \mathrm{a}$ & $194,2 \mathrm{a}$ & $239,7 \mathrm{a}$ \\
\hline$(75+750) \mathrm{g} \mathrm{ha}^{-1}$ & $110,0 \mathrm{a}$ & $189,9 \mathrm{a}$ & $236,8 \mathrm{a}$ \\
\hline Metribuzin $875 \mathrm{~g} \mathrm{ha}^{-1}$ & $104,2 \mathrm{a}$ & $181,7 \mathrm{a}$ & $234,3 \mathrm{a}$ \\
\hline BNT 0,05 & 14,1 & 22,4 & 20,3 \\
\hline
\end{tabular}

Keterangan: Nilai tengah yang diikuti oleh huruf yang sama pada kolom yang sama tidak berbeda menurut uji BNT pada taraf nyata $5 \%$. 
brasiliensis pada 30, 60, dan 90 HSA. (2) Herbisida flumioxazin dosis 200 dan $250 \mathrm{~g} \mathrm{ha}^{-1}$ efektif dalam mengendalikan gulma Mimosa invisa pada 30, 60, dan 90 HSA. (3) Herbisida flumioxazin semua taraf dosis yang diuji $\left(75-250 \mathrm{~g} \mathrm{ha}^{-1}\right)$ tidak berpengaruh terhadap pertumbuhan (populasi dan tinggi) tanaman tebu pada 30, 60, dan 90 HSA.

\section{DAFTAR PUSTAKA}

Alfredo, N, D. R. J.,Sembodo, dan N., Sriyani. 2012. Efikasi Herbisida Pratumbuh Metil Metsulfuron Tunggal dan Kombinasinya dengan 2,4-D, Ametrin, atau Diuron terhadap Gulma pada Pertanaman Tebu (Saccharum officinarum L.) Lahan Kering. Jurnal Agrotropika 17(1): 2934

Azania, C. A. M., A.R., Schiavett, dan F.S., Zera. 2010. Evaluation of herbicides applied on sugar cane during rainy season in Brazil. Revista Brasileira de Herbicidas: 1-8.

Ducar, J. T., S. B. Clewis, J. W. Wilcut, dan D. L. Jordan. 2009. Weed Management Using Reduced Rate Combinations of Diclosulam, Flumioxazin, and Imazapic in Peanut. Weed Science Society of America 23(2): 236-242.

Flessner M. L., J. S. Mcelroy, J. H. Baird, dan B. D. Barnes. 2013. Utilizing Flumioxazin for Annual Bluegrass (Poa annua) control in Bermudagrass Turf.Amerika: Weed Science Society of America 27(3): 590-595.
Grichar, W.J., P. A. Dotray, dan M. R., Baring. 2013. Peanut Cultivar Response to Flumioxazin Applied Preemergence and Imazapic Applied Postemergence. International Journal of Agronomy 2013(5): 1-5

Jordan, D. L., S. H. Lancaster, dan J. E. Lanier. 2009. Peanut and Eclipta (Eclipta prostrata) Response to flumioxazin. Weed Technology 23(2): 231235

Sembodo,D. R. J.2010.Gulma dan Pengelolaannya. Graha Ilmu. Yogyakarta. $168 \mathrm{hlm}$.

Tomlin, C. D. S. 2011. The e Pestiside Manual (thirteenth edition) version 3.1. British Corp Protection Council. $1.606 \mathrm{hlm}$.

Vasilakoglou, I., K. Dhima, K. Paschalidis, dan T. Gatsis. 2013. Field bindweed (Convolvulus arvensis L.) and redroot pigweed (Amaranthus retroflexus L.) control in potato by pre- or post-emergence applied flumioxazin and sulfosulfuron. Chilean Journal Of Agricultural Research 73(1). 24 30.

Wijaya, R. B., P. Yudono, dan R. Rogomulyo. 2012. Uji Efikasi Herbisida Pratumbuh untuk Pengendalian Gulma Pertanaman Tebu (Saccharum officinarum L.).http://journal.ugm.ac.id/ index.php/jbp/artikel/download/1350/pdf_2. diakses tanggal 30 Septemper 2013. 